\title{
The effects of lymph node dissection techniques on the survival of geriatric patients with non-small cell lung cancer
}

\author{
Mustafa Vedat Doğru ${ }^{1}$ iD, Celal Buğra Sezen ${ }^{1}$ iD, Cemal Aker ${ }^{1}$ (D) \\ Fatma Tokgöz Akyıl² (D) Muzaffer Metin¹ (D),
}

1 Health Sciences University, Yedikule Chest Diseases and Thoracic Surgery Training and Research Hospital, Department of Thoracic Surgery, Istanbul, Turkey

2 Health Sciences University, Yedikule Chest Diseases and Thoracic Surgery Training and Research Hospital, Department of Chest Diseases, Istanbul, Turkey

\begin{abstract}
Background: Lymph nodes are the most important prognostic factors in lung cancer. Controversy still continues on lymph nodes prognosis. This study aims to evaluate the effects of lymph node dissection techniques on survival in geriatric patients.

Methods: The study was conducted retrospectively in patients who were operated on for non-small cell lung cancer (NSCLC) between 2007 and 2016. Lobe-specific lymph node dissection (LsLND) was performed in 77 patients, while complete (systematic) lymph node dissection (SLND) was performed in 206 patients.

Results: A total of 283 patients were included in the study, of which 258 were male $(91.2 \%)$ and 25 were female $(8.8 \%)$. The median age of the patients was 69 years (IQR: 65-84). The mean survival time of the patients was 46 months, and the 5-year survival rate was $38.9 \%$. The survival rate in $\mathrm{pN} 2$ disease was $15.6 \%$, while the survival rate in pN0 disease was $46 \%$. While the 5-year survival rate was $34.4 \%$ in patients who underwent lobe-specific lymph node sampling, it was $40.5 \%$ in patients who underwent systematic lymph node dissection $(\mathrm{p}=0.147)$.

Conclusions: As a result of our study, no difference was found in terms of survival between lobe-specific lymph node dissection or systematic lymph node dissection in the geriatric age group. Especially pN2 disease, histopathological, and resection width were observed among the most important prognostic factors affecting survival. Therefore, we think lobe-specific lymph node sampling may be preferred instead of performing complete-systematic lymph node dissection in advanced ages because of less morbidity.
\end{abstract}

Keywords: Carcinoma, Non-Small-Cell Lung, Survival Rate, Prognosis, Lymph Nodes.

Cite this article as: Doğru MV, Sezen CB, Aker C, Tokgöz Akyll F, Metin M. The effects of lymph node dissection techniques on the survival of geriatric patients with non-small cell lung cancer. Arch Curr Med Res. 2022;3(1):13-17

\section{Corresponding Author}

Mustafa Vedat Doğru, Health Sciences University Yedikule Chest

Diseases and Thoracic Surgery Training and Research Hospital,

Department of Thoracic Surgery, Istanbul, Turkey

E-mail: drmvedatdogru@hotmail.com
Content of this journal is licensed under a Creative Commons Attribution-NonCommercial 4.0 International License. 


\section{INTRODUCTION}

Lung cancers remain the leading cause of cancer-related mortality $(1,2)$. In therapy, surgery has been accepted as the main procedure for the early stages. Surgical treatment is particularly avoided in elderly patients with lung cancer. The fragility of vascular structures of the elderly, the loss of elasticity of lung parenchyma, and high comorbidities are the main reasons for surgeons to avoid surgical treatments. However, patients over 75 years old are compared with younger ages, and it is seen that curative lung resection has been performed $22 \%$ less than elderly patients(3).

Today, there have been ongoing debates about lymph nodes which are one of the most crucial prognostic factors in lung cancer. It can be seen that there are different views and approaches in the literature related to the issue. There has not been a clear consensus about lymph node dissection, especially in the geriatric age group yet (4-6). While some suggest that it increases the complications and does not have an effect on survival and due to this reason, they offer simple lymph node dissection; some others think that complete lymph node dissection will increase the chance of survival of the patient.

In this study, our aim was to evaluate the effects of lymph node dissection techniques on the survival of geriatric patients.

\section{MATERIALS AND METHODS}

This study has been retrospectively conducted with patients who had operations due to non-small cell lung cancer (NSCLC) between 2007 and 2016. Patients with mortality, patients who received neoadjuvant therapy, and patients whose data cannot be reached have been excluded from the study. Two hundred eighty-three patients with NSCLC are evaluated in this study. The geriatric group is defined as over 65 years old in the study. All patients in the study are required a thoracic CT in order to evaluate the preoperative tumor localization. Positron emission tomography and cranial magnetic resonance imaging have been used to evaluate distant metastases. Respiratory function tests and carbon monoxide diffusion capacity (DLCO) have been used so as to evaluate respiratory capacities. As all the patients are geriatric, they have been examined by cardiology pre-operatively.
The lymph node dissections of the patients in the study are evaluated in two groups. While lobe-specific lymph node dissection has been performed in 77 patients (LN1), complete (systematic) lymph node dissection has been performed in 206 patients (LN2). The lymph node dissection techniques have been accepted as defined by Watanabe (7).

This study was approved by the clinical research ethics committee of the Health Sciences University, Yedikule Chest Diseases and Thoracic Surgery Training and Research Hospital (Date: 29.07.2021 number: 2021/141) and written consent was obtained from all patients participating in the study.

\section{Statistical Method:}

Statistical analyses were done by using IBM SPSS Windows 22.0. While numeric variables were determined by mean \pm standard deviation and median (min-max), categorical variables were determined by number and percentage. Kaplan Meier analysis was used to evaluate the survival rate, and log-rank analysis was used to compare factors. In this study, the level of significance was accepted as $\mathrm{p}<0.05$.

\section{RESULTS}

In the study, 258 male (91.2\%) and 25 female (8.8\%) patients were included. The median age of the patients was 69 years (IQR: 65-84). While pneumonectomy was performed on 61 patients $(21.6 \%)$, lobectomy was performed on 222 patients $(78.7 \%)$. Also, while right resection was performed on 155 patients (54.8\%), left resection was performed on 128 patients $(45.2 \%)$. The mean diameter of the tumors was found to be $4.5 \pm 2.3$ centimeters. Systematic (complete) lymph node dissection was performed in 206 patients, and lobe-specific lymph node dissection was performed on 77 patients $(27.2 \%)$. There were $124(72.1 \%)$ patients with pN0, 58 (73.4\%) patients with $\mathrm{pN} 1$, and 24 patients $(75 \%)$ with $\mathrm{pN} 2$, who underwent systematic lymph node dissection. Forty-eight (27.9\%) patients with $\mathrm{pN} 0,21(26.6 \%)$ patients with $\mathrm{pN} 1$, and 8 patients $(25 \%)$ with pN2 underwent lobe-specific lymph node dissection ( $\mathrm{p}=0.934)$. Demographic, surgical, and histopathologic properties of the patients are shown in Table 1. 
Table 1. Demographic and surgical characteristics of the patients

\begin{tabular}{|c|c|c|c|}
\hline \multicolumn{2}{|l|}{ Variables } & $\mathbf{n}$ & $\%$ \\
\hline \multirow{2}{*}{ Gender } & Male & 258 & 91.2 \\
\hline & Female & 25 & 8.8 \\
\hline Age (Median) & Year & \multicolumn{2}{|c|}{69} \\
\hline \multirow{2}{*}{ Side } & Right & 155 & 54.8 \\
\hline & Left & 128 & 45.2 \\
\hline \multirow{2}{*}{ Operation } & Lobectomy & 222 & 78.4 \\
\hline & Pneumonectomy & 61 & 21.6 \\
\hline \multirow{3}{*}{$\mathrm{pN}$ Status } & pN0 & 172 & 60.8 \\
\hline & $\mathrm{pN} 1$ & 79 & 27.9 \\
\hline & $\mathrm{pN} 2$ & 32 & 11.3 \\
\hline \multirow{3}{*}{ Histopathology } & Adenocarsinoma & 112 & 39.6 \\
\hline & $\begin{array}{l}\text { Squamous Cell } \\
\text { Carsinoma }\end{array}$ & 158 & 55.8 \\
\hline & Other & 13 & 4.6 \\
\hline \multirow{3}{*}{ Stage } & I & 88 & 31.1 \\
\hline & II & 100 & 35.3 \\
\hline & III & 95 & 33.6 \\
\hline \multirow{2}{*}{$\begin{array}{l}\text { Lymph Node } \\
\text { Dissection } \\
\text { Technique }\end{array}$} & LN1 & 77 & 27.2 \\
\hline & LN2 & 206 & 72.8 \\
\hline
\end{tabular}

LN-1: lobe-specific lymph node dissection, LN-2: systematic lymph node dissection

The average survival time of the patients were 46 months, and the five-year survival rate was found to be $38.9 \%$. While the five-year survival rate was $26.2 \%$ in the pneumonectomy patients, it was $42.4 \%$ in lobectomy patients $(\mathrm{p}=0.005)$. The survival rate was $41.6 \%$ in rightoperated patients; on the other hand, it was determined as $54.6 \%$ in left-operated patients. It was determined that there was no statistically significant difference $(\mathrm{p}=0.057)$. While pN2 patient survival was $15.6 \%$, pN0 patient survival was detected as $46 \%$. The five-year survival rate was $34.4 \%$ in the patients for whom lobe-specific lymph node dissection has been done. On the other hand, the survival rate was determined to be $40.5 \%$ in patients for whom systematic lymph node dissection was performed $(\mathrm{p}=0.147)$. In the analysis of survival performed by excluding pN2 and pneumonectomy patients, the 5-year survival rate in the LN1 group was $40.7 \%$, while the 5 -year survival rate in the LN2 group was $47 \%$. There was no statistically significant difference between the groups $(\mathrm{p}=0.135)$. Prognostic factors that affect the survival rate are shown in Table 2.

\section{Table 2. Prognostic factors affecting survival}

\begin{tabular}{|c|c|c|c|c|c|}
\hline \multicolumn{2}{|l|}{ Variables } & $\begin{array}{c}5 \text { Year } \\
\text { Survival } \\
(\%)\end{array}$ & $\begin{array}{l}\text { Median } \\
\text { Month }\end{array}$ & $\begin{array}{c}\% 95 \\
\mathrm{CI}\end{array}$ & p-Value \\
\hline \multirow{2}{*}{ Gender } & Male & 39.2 & 48 & $39-52$ & \multirow{2}{*}{0.873} \\
\hline & Female & 36 & 46 & $28-67$ & \\
\hline \multirow{2}{*}{ Side } & Right & 41.6 & 52 & $45-58$ & \multirow{2}{*}{0.057} \\
\hline & Left & 54.6 & 37 & $22-51$ & \\
\hline \multirow{2}{*}{ Operation } & Lobectomy & 42.4 & 50 & $42-57$ & \multirow{2}{*}{0.005} \\
\hline & Pneumonectomy & 26.2 & 26 & $11-40$ & \\
\hline \multirow{3}{*}{ 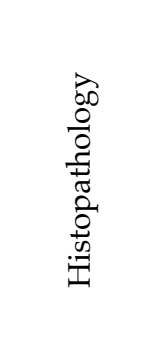 } & Adeno Carsinoma & 35.3 & 41 & $32-49$ & \multirow{3}{*}{0.008} \\
\hline & $\begin{array}{l}\text { Squamous Cell } \\
\text { Carcinoma }\end{array}$ & 43.4 & 52 & $42-61$ & \\
\hline & $\begin{array}{l}\text { Other (Large } \\
\text { Cell and } \\
\text { Adenosquamous } \\
\text { cell carcinoma) }\end{array}$ & 15.4 & 12 & $0-28$ & \\
\hline \multirow{2}{*}{$\begin{array}{l}\text { Lymph } \\
\text { node }\end{array}$} & $\mathrm{pN} 0$ & 46 & 55 & $45-64$ & \multirow{2}{*}{0.002} \\
\hline & pN1-pN2 & 27.9 & 37 & $25-48$ & \\
\hline \multirow{2}{*}{$\begin{array}{l}\text { Lymph } \\
\text { Node } \\
\text { Dissection } \\
\text { Technique }\end{array}$} & LN1 & 34.4 & 40 & $21-58$ & \multirow[t]{2}{*}{0.147} \\
\hline & LN2 & 40.5 & 47 & $39-52$ & \\
\hline
\end{tabular}

CI: Confidence Interval, LN-1: lobe-specific lymph node dissection, LN-2: systematic lymph node dissection

Based on the multivariate analysis of factors affecting survival, pN1-N2 status and large cell and adenosquamous cell carcinomas were found as poor prognostic factors. Multivariate analyses of prognostic factors affecting survival rate are shown in Table 3. 
Table 3. Multivariate analysis of prognostic factors affecting survival

\begin{tabular}{|c|c|c|c|c|}
\hline \multicolumn{2}{|l|}{ Variables } & HR & $\begin{array}{c}\% 95 \\
\mathrm{CI}\end{array}$ & p-Value \\
\hline Operation & Pneumonectomy & 1.34 & $0.9-1.9$ & 0.123 \\
\hline \multirow{3}{*}{ 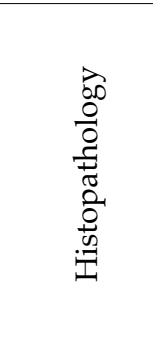 } & Adenocarsinoma & & & 0.004 \\
\hline & $\begin{array}{l}\text { Squamous Cell } \\
\text { Carcinoma }\end{array}$ & 0.77 & $0.5-1.0$ & 0.102 \\
\hline & $\begin{array}{l}\text { Other (Large } \\
\text { Cell and } \\
\text { Adenosquamous } \\
\text { cell carcinoma) }\end{array}$ & 2.01 & $1.1-3.6$ & 0.021 \\
\hline $\begin{array}{l}\text { Lymph } \\
\text { node }\end{array}$ & pN1-pN2 & 1.45 & $1.0-2.0$ & 0.023 \\
\hline
\end{tabular}

CI: Confidence Interval

\section{DISCUSSION}

The situation of the lymph node is one of the most important prognostic factors in lung cancers. Today, systematic lymph node dissection is one of the standard procedures in lung resections. European Society of Thoracic Surgeons (ESTS) suggests systematic lymph node dissection for complete resection to all patients(8). ESTS recommend at least three mediastinal lymph node (at least one of them subcarinal), and at least six lymph node must dissect for systematic lymph node dissection. However, in early lung cancers, radical dissection occurs more complications to the patients. Previous studies have shown that lobe-specific lymph node dissections have been foreseen as more practical than systematic lymph node dissections in lung cancers.

Sugi et al. have stated that among the patients for whom systematic lymph node dissection has been performed, the morbidity is higher than the ones for whom sampling has been done, and they also notified that a longer time is required intraoperatively (9). Particularly, they have stated that the operation time has been prolonged in systematic lymph node dissections on the left. There have been many publications from Japan that report that the best way to detect the metastasis rate (N-positive) in cancers is performed systematic lymph node dissection. Especially in peripheral tumors, it is a 10-25\% possibility to see lymph node metastasis, and for this reason, systematic lymph node dissection is required to correct staging $(9,10)$.On the other hand, Gajra et al.(11) have detected a difference between random sampling lymph node dissection and systematic lymph node dissection related to the survival of the patients. While the five-year survival rate is $56.4 \%$ in random sampling lymph node dissections, it has been 83.3\% in systematic lymph node dissections. Besides, the selective lymph node dissection technique has been a more prioritized choice in minimally invasive surgeries $(12,13)$. Especially, there have been some approaches that support using this technique not to increase morbidity among elderly patients. However, this approach is not accepted as a standard technique. Also, Hokage has stated that the survival rates of subcarinal lymph node metastasis positive upper lobe tumors have a worse course than isolated upper mediastinal lymph node metastasis. For this reason, Aokage does not recommend a selective lymph node dissection technique (14). Similarly, Ichinose and Okada have also determined that subcarinal lymph nodes have a worse course than superior mediastinal lymph nodes related to survival rates $(15,16)$. Tulay et al. (17), they stated that intraoperative sentinel lymph node mapping would provide better information about the lymphatic drainage of the tumor, assist the surgeon in performing a better lymphadenectomy, and enable the detection of occult and micrometastatic disease for nonsmall cell lung cancer. Also, Turna et al.(18) mentioned sentinel lymph node is also defined as the most common involved of mediastinal lymph node station or stations for each pulmonary lobe. $96.5 \%$ of the patients of the right upper lobe tumors have lower paratracheal lymph nodes. In our study, we recommend removing sentinel lymph nodes at the lob-specific lymph node dissection.

In this study, a statistical difference has not been detected between systematic lymph node dissection technique and lobe-specific lymph node dissection technique. While the five-year survival rate has been $40.5 \%$ in systematic lymph node dissection, it has been $34.4 \%$ in lobe-specific lymph node dissection technique.

In this study, it has been found out that the most important factor that affects the survival of geriatric patients is the width of resection, large cell carcinoma, and pN2. While the five-year survival rate of the patients for whom $\mathrm{pN} 0$ is detected is $46 \%$, this rate is $27.9 \%$ for whom pN1-2 is detected. In their study, Sezen et al. have not been found out a relation between the resection type and survival rates(19). It has been found out that while the five-year survival rate of the patients with lobectomy is $44.6 \%$, it is $23.4 \%$ in the patients with pneumonectomy. It is thought that there has been a statistically non-significant result in this study due to the low number of patients. Besides, Li et al. have been detected that the survival rate of patients with lobectomy 
is higher than the ones with pneumonectomy. It has been observed that the five-year survival rate is $25.7 \%$ for the patients with lobectomy, and it is $7.3 \%$ for the patients with pneumonectomy $(\mathrm{p}<0.001, \mathrm{HR}: 1.96)$ (4).

This is a retrospective study by definition, and also there might be a bias due to the low number of patient groups that are included in the study. The limitation increases because the number of women patients is also low. Moreover, it is a single-center study, and a lack of disease-free survival analysis might cause limitations.

In this study, the lack of clinical staging data also creates bias. In our clinical practice, we don't have any consensus about systematic lymph node dissection and lobe-specific lymph node dissection techniques. The surgeons' preference for the lymph node dissection technique can cause heterogeneity in the study. Also, in this study, our aim is to evaluate the long-term results of the lymph node dissection. However, we didn't evaluate short-term outcomes in this study; for this reason, this increases the selection bias of the study.

In this study, as a result, it has been found out that there is no difference between lobe-specific lymph node dissection and systematic lymph node dissection in geriatric patients in terms of survival rates. It has been observed that pN2 disease, histopathology, and the type of resection are the most important prognostic factors that affect the survival rates. Although ESTS recommended systematic lymph node dissection for lung cancer; we think that both surgical techniques can be applied to elderly patients since there is no difference in survival rates between lymph node dissection techniques. However, multi-centered and prospective studies are still required.

\section{Declarations}

The authors received no financial support for the research and/or authorship of this article. There is no conflict of interest.

This study was approved by the clinical research ethics committee of the Health Sciences University, Yedikule Chest Diseases and Thoracic Surgery Training and Research Hospital (Date: 29.07.2021 number: 2021/141) and written consent was obtained from all patients participating in the study.

\section{REFERENCES}

1. Dogru MV, Sezen CB, Erdogu V, Aker C, Alp A, Erduhan S, Et al. Prognostic factors of operated stage 1 non-small cell lung cancers: A tertiary center long-term outcomes. Med Bull Haseki 2021;59:221-227

2. Sezen AI, Sezen CB, Sokulmez Yildirim S, Dizbay M, Ulutan F. Cost analysis and evaluation of risk factors for postoperative pneumonia after thoracic and cardiovascular surgery: a single-center study. Curr Thorac Surg 2019;4(2):56-62.

3. Jemal A, Bray F, Center MM, Ferlay J, Ward E, Forman D. Global cancer statistics. CA: a cancer journal for clinicians. 2011;61(2):69-90.

4. Li Z, Chen W, Xia M, Liu H, Liu Y, Inci I, et al. Sleeve lobectomy compared with pneumonectomy for operable centrally located non-small cell lung cancer: a meta-analysis. Transl Lung Cancer Res. 2019;8(6):775-786.

5. Darling GE. Lymph node assessment in early stage non-small cell lung cancer lymph node dissection or sampling? Gen Thorac Cardiovasc Surg. 2020;68(7):716-724.

6. Dezube AR, Mazzola E, Bravo-Iñiguez CE, De León LE, Rochefort MM, Bueno R, et al. Analysis of lymph node sampling minimums in early stage non-small-cell lung cancer. Semin Thorac Cardiovasc Surg. 2021;33(3):834-845.

7. Watanabe S. Lymph node dissection for lung cancer: past, present, and future. Gen Thorac Cardiovasc Surg. 2014;62(7):407-14.

8. Lardinois D, De Leyn P, Van Schil P, Porta RR, Waller D, Passlick B, et al. ESTS guidelines for intraoperative lymph node staging in non-small cell lung cancer. Eur J Cardiothorac Surg. 2006;30(5):787-92.

9. Sugi K, Nawata K, Fujita N, Ueda K, Tanaka T, Matsuoka T, et al. Systematic lymph node dissection for clinically diagnosed peripheral non-small-cell lung cancer less than $2 \mathrm{~cm}$ in diameter. World J Surg. 1998;22(3):290-4; discussion 294-5.

10. Hata E. Rationale for extended lymphadenectomy for lung cancer. Theor Surg. 1990;5:19-25.

11. Gajra A, Newman N, Gamble GP, Kohman LJ, Graziano SL. Effect of number of lymph nodes sampled on outcome in patients with stage I non-small-cell lung cancer. J Clin Oncol. 2003;21(6):1029-34.

12. Watanabe S, Asamura H, Suzuki K, Tsuchiya R. The new strategy of selective nodal dissection for lung cancer based on segment-specific patterns of nodal spread. Interact Cardiovasc Thorac Surg. 2005;4(2):106-9.

13. Kato H, Ichinose $\mathrm{Y}$, Ohta M, Hata E, Tsubota N, Tada H, et al; Japan Lung Cancer Research Group on Postsurgical Adjuvant Chemotherapy. A randomized trial of adjuvant chemotherapy with uracil-tegafur for adenocarcinoma of the lung. N Engl J Med. 2004;350(17):1713-21.

14. Aokage K, Yoshida J, Ishii G, Hishida T, Nishimura M, Nagai K. Subcarinal lymph node in upper lobe non-small cell lung cancer patients: is selective lymph node dissection valid? Lung Cancer. 2010;70(2):163-7.

15. Okada M, Tsubota N, Yoshimura M, Miyamoto Y, Matsuoka H. Prognosis of completely resected pN2 non-small cell lung carcinomas: What is the significant node that affects survival? J Thorac Cardiovasc Surg. 1999;118(2):270-5

16. Nakao M, Ichinose J, Matsuura Y, Okumura S, Mun M. Outcomes after thoracoscopic surgery in octogenarian patients with clinical N0 nonsmall-cell lung cancer. Jpn J Clin Oncol. 2020;50(8):926-932.

17. Tulay CM, Sivrikoz MC, Ak İ, Çiftçi ÖD, Akçay EÖ, Dündar E. Sentinel lymph node mapping in early stage non-small cell lung carcinoma. Turk Gogus Kalp Dama. 2013;21:416-21.

18. Turna A, Solak O, Kilicgun A, Metin M, Sayar A, Gürses A. Is lobe-specific lymph node dissection appropriate in lung cancer patients undergoing routine mediastinoscopy? Thorac Cardiovasc Surg. 2007;55(2):112-9.

19. Sezen CB, Gokce A, Kalafat CE, Aker C, Tastepe AI. Risk factors for postoperative complications and long-term survival in elderly lung cancer patients: a single institutional experience in Turkey. Gen Thorac Cardiovasc Surg. 2019;67(5):442-449. 